\title{
Cooperative Donor Registry
}

National Cancer Institute

\section{Source}

National Cancer Institute. Cooperative Donor Registry. NCI Thesaurus. Code C132253.

A formal business relationship between donor registries allowing for tissue matching against the pool of donors created by all participating registries. 